\title{
GLAZBENO TVORIVO ROMANA DVA SVIJETA VJENCESLAVA NOVAKA
}

Sintija Čuljat

Filozofski fakultet Sveučilišta u Rijeci

Sveučilišna avenija 4

HR 51000 Rijeka

sculjat@ffri.uniri.hr
UDK: 78.071Novak, V. 821.163.42.09Novak, V. Prethodno priopćenje Ur.: 2019-12-24

U psihološkom romanu prijelaza stoljeća Dva svijeta glazbenik Amadej Zlatanić ogleda svoj stvaralački potencijal u kulturnom arealu Austro-Ugarske Monarhije.

Domaći prostor zanijekane pripadnosti oslabljuje vidljivost hrvatskog imena, a glazbenom naobrazbom osnažen Zlatanićev umjetnički integritet ugrožavaju društvene konvencije. Junakovu inicijaciju u glazbeni univerzum Novak ostvaruje sinkretičnim metajezikom glazbene umjetnosti.

Muzikologinja Sanja Majer-Bobetko pronašla je Novakov pregled europske glazbene povjesnice. Romanom Dva svijeta Novak primjenjuje vlastito propedeutičko iskustvo prijenosa glazbenih u pripovjedne oblike. Novakova reprezentacija dvojnosti pojavnoga i zamišljenoga svijeta gradbena je dionica romana o postajanju umjetnikom. Prevodeći jezik glazbe u protomodernistički pripovjedni iskaz, Novak propitkuje perspektive hrvatskoga umjetničkoga identiteta u rečenom kulturnopovijesnome poretku.

Ključne riječi: Vjenceslav Novak, Dva svijeta, povijest glazbe, roman, sinkretizam

\section{Uvod}

U Novakovu psihološkom romanu s natruhama modernizma Dva svijeta, objavljenom 1901. godine u svescima 242. - 244. Zabavne knjižnice Matice hrvatske, tegobno glazbenoumjetničko samoostvarivanje protagonista Amadeja Zlatanića spram vrijednosnoga poretka Austro-Ugarske Monarhije zadobiva svoju središnju metaforu u polarizaciji materijalne i nematerijalne zbilje. Iskliznuće iz poznatoga svijeta prema isključivim zakonitostima glazbe čini ga tvorcem mogućega glazbenog univerzuma koji na jedinstven način povezuje apolonijsku ravnotežu glazbena znanja i dionizijsku opijenost pobuđenih čula.

Roman Dva svijeta opojmljuje Novakovu zaokupljenost načinima izvedbe, prijenosom i prihvatom autentična glazbeničkog iskustva iz 
partikularna hrvatskoga položaja u europskome kulturnome prostoru fin de sièclea. Kada Novak govorom iz domene glazbe posvjedočuje naponu Zlatanićeva osobnog umjetničkoga pothvata, on pripovjedno oblikuje stanovitu sinegdohu ukupnoga duhovnog i mentalitetnoga stanja hrvatskoga subjekta uglavljenau matricu srednjoeuropskih kulturnih identitetskih obrazaca.

Pripravljajući gotovo istodobno s gradivom romana Dva svijeta rukopis europske povijesti glazbe, Novak nudi jedinstveni referencijalni ključ za razumijevanje stvorenih značenja i značenjskih elipsa u tomu pripovjednomu djelu. Fragmenti Novakova teksta iz područja glazbene historiografije u nastajanju, osobito oni o naravi onodobnoga hrvatskoga glazbenoga korpusa te označaju hrvatskih protagonista na europskome glazbenome polju, zaživljuju u dionicama njegova romana. Odjeci višekratno zapriječivane Novakove potvrde kroz obuhvatnu karijeru glazbenika, lektora glazbene škole Hrvatskoga glazbenoga zavoda i prozaika u hrvatskome zakutku Europe dodatno impregniraju Zlatanićev ispovjedni iskaz (Zlatanić, čudo od djeteta, započinje kao ishitrilac, ili vješt izvoditelj glazbe za orgulje). Svako poreknuće posebnosti Amadejeva glazbotvorstva za račun nedostatnih starih znanja i preuzetih imenovanja za Novaka je kao integralnog Europejca, hrvatskog odvjetka europske tradicije, senjskoga sina češko-njemačkih korijena neprihvatljivo osiromašivanje, ekscesna zloporaba univerzalnog jezika glazbe.

\section{Oknjiževljivanje glazbe u romanu Dva svijeta}

Amadejeva glazbena estetika izrasla je na podlozi glazbene teorije, discipline duha ravnoteže, suzvučja, mjere i razdiobe. Novakov će protagonist tako zagovarati slobodu glazbene ideje upravljane zakonima glazbena nauka. Načelo svojega učitelja Jahode, po kojemu tek poznavanje pravila glazbene umjetnosti jamči slobodu umjetnika, Amadej nasljeduje predanom sačimbom programne, umjetničke glazbe nasuprot ograničenjima slobode glazbenog izraza što ih pred glazbenika neznalački postavlja vlastita zajednica. Razlažući Amadejevo pristajanje uz uporišna mjesta svoje glazbene inicijacije do vizije apsolutne i od svega odriješene glazbe, Novak izvodi stajališta o glazbi kao univerzalnoj umjetnosti koja se ne dade vrednovati kriterijima pripadnosti autora metropoli ili periferiji niti podložiti predsudovima o autorstvu.

Novak pripovjedač, teoretik i tumač glazbopisa briše izvanumjetničke kriterije prisvajanja glazbenoga gradiva u dijelu romana u kojem njemački nakladnik muzikalija pristane tiskati ciklus Amadejevih skladbi ako se odrekne svojega imena, na što on radije iz nužde prihvaća loše plaćen nadničarski posao 
anonimnog aranžera tuđih kompozicija za orkestar, spoznavši ukorijenjenost europocentričnih vrijednosnih odrednica kojima se ustanovljuje identitet glazbenika drugotnog statusa dospjela iz malog naroda. Konstituent Amadejeve glazbenoumjetničke osobnosti, tj. supstancija njegova umjetničkog poslanja poništava se svedena na puki zanat: za njom slijedi rasap ličnosti poreknuta autorstva, značaja i mjesta u kolektivnome sjećanju.

Novakov glazbeni metajezik i literarizacija glazbotvoračkoga postupka u ovom romanu razvijaju irealni, fluidni "protusvijet" kakav se u razdoblju moderne promišljao kao nadomjestak realističkome predstavljačkome modelu. ${ }^{1}$ Umjetni svijet Zlatanićeve završne glazbenoumjetničke vizije iznikao je iz stilskih smjernica art nouveaua o premoći stvaralaštva nad prirodom. Novakova zamisao o nekovrsnoj konvergenciji glazbene povijesti i književnosti navezana je na "umjetničke vrste proizišle iz secesijskog suglasja raznih grana umjetnosti, iz modernog sinkretizma". ${ }^{2} \mathrm{~K}$ tome, riječ je o postupcima koji, iako sinkronizirani s europskim svjetonazorskim usmjerenjima umjetnosti radi umjetnosti, upućuju na praznine i diskrepanciju u kulturnoj afirmaciji hrvatskih prostora u širem europskom okružju razdoblja secesije. Izbor iz povjesnice europske glazbe, ali i programatski zagovor filozofije nove glazbe u romanu promeće se u način ustanovljenja hrvatskoga stvaralačkog identiteta prema parametrima kanonskog u europskoj glazbi Novakova doba.

Oknjiževljivanjem glazbe u romanu Dva svijeta figure i ritam glazbenih stavaka Novak ugađa s pripovjednim ritmom, izvodeći glazbeni ispis za modernistički roman ili pripovjedno tkivo s onoga drugoga, glazbenoga svijeta. Višeznačnost Novakova romanesknoga postupka izrasta upravo iz činjenice da je u završnome desetljeću devetnaestoga stoljeća, od godine 1894. usporedno s ovim romanom nastajao njegov rukopis prve hrvatske opće glazbene povjesnice, koju je u Knjižnici Muzičke akademije u Zagrebu, kategorija 7006, 1994. godine otkrila i pod naslovom Povijest glazbe priredila muzikologinja Sanja Majer-Bobetko. ${ }^{3}$ Ova rukopisna, nikad objavljena Povijest glazbe u tri razdoblja (Glazbe starih naroda do kršćanske dobe, Kršćanske glazbe do 1600. godine i Doba procvata dramatske i klasične glazbe od 1600. do danas) $)^{4}$ bilježi i europskom glazbotvorstvu supostavlja priloge za glazbenu povijest južnoslavenskih naroda, upravljajući pritom

\footnotetext{
${ }^{1}$ N. BATUŠIĆ et al., 2002, 17, 195.

${ }^{2}$ N. BATUŠIĆ et al., 2002, 182.

${ }^{3}$ Vidi S. MAJER-BOBETKO, 1993/1994.

${ }^{4}$ S. MAJER-BOBETKO, 1993/1994, 6.
} 
pogled naprinose hrvatskih dionika, skladatelja, glazbenih historiografa i poučavatelja glazbe od ilirskoga preporoda do kraja devetnaestoga stoljeća, naobraženih na učilištima Beča, Pešte i Praga, kojima je Novak kao praški konzervatorist i sam pripadao.

Stekavši zvanje orguljaša, nastavnika pjevanja i teorije glazbe na Praškome konzervatoriju 1886., nastavio je Novak glazbenopedagoški rad pri Muškoj učiteljskoj školi i Hrvatskome glazbenom zavodu. Iz toga razdoblja nastaju njegovi udžbenici glazbene harmonije, priručnici, rasprave, harmonizirani starohrvatski crkveni napjevi te glazbene kritike, dok nam nepoznatim ostaje Novakov skladateljski opus. Na pitanje krije li autorova ostavština, među ostalim i prinos glazbi za orgulje, Novak nudi umjetnički odgovor romanom Dva svijeta u kojem razvija načelo glazbe u književnosti ili "ispripovijedane glazbe", 5 iznoseći jedinstveni pripovjedni ogled pretapanja novostvorenoga, fiktivnoga glazbenog oblika i književnoga sadržaja.

Romanom Dva svijeta zaživljuju Novakovi uvidi u neodvojivost znanosti o povijesti glazbe od glazbene teorije, estetike glazbe, glazbotvorstva, tj. glazbene stilistike. Ako je priređujući svoje glazbenopovijesno djelo Novak propitkivao prijenos odabranoga glazbenoga nazivlja, objavom romana $D v a$ svijeta on ga primjenjuje u punini, postavljajući u kontrapunkt svoj glazbeni zapis i pripovjedni iskaz. Iz načina na koji Novak oblikuje glazbeno gradivo u romanu, izdvajajući po njemu središnje pojmove glazbene estetike, iščitava se zanimanje za prijenos glazbe u drugi simbolički sustav, za svojevrsni glazbeni elocutio izveden s pomoću tek zaživjelih sastavnica hrvatskoga glazbenoga nazivlja i odjeka književnih slika iz hrvatskoga glazbenoga repozitorija. Pritom pripovjedač Novak problematizira stajališta devetnaestotoljetnih glazbenih teoretika formalista Picha i Hänslicka ${ }^{6}$, i glazbenoj formi traži podmet ili sadržaj kako ona ne bi postala sama sebi svrhom. Riječju, Novak se okreće propitkivanju granica književnosti i glazbe, prepoznajući mogućnosti doticaja, kontigviteta književnoga i teorijsko-glazbenoga polja u artikulaciji hrvatske umjetničke glazbe i umjetničkog romana, što potkrepljuju naglasci na autorskoj samosvojnosti umjetničke književnosti iz koje Amadej crpi gradivo za svoje glazbene gradnje: "ni najljepša narodna pjesma (...) nije pjevanje iz Gundulićeva 'Osmana', nije Preradovićeva 'Oda' - kao što ni najljepša narodna pripovijest nije stranica Šenoina historična romana..."7

${ }^{5}$ V. ŽMEGAČ, 2003,173.

${ }^{6}$ S. MAJER-BOBETKO, 1993/4, 11.

${ }^{7} \mathrm{~V}$. NOVAK, 2009, 400. 


\section{Glazbena načela Vjenceslava Novaka u pripovjednom eksperimentu}

U traganju za estetičkoglazbenim sadržajem koji bi najprimjerenije povezao glazbenu literaturu i stvaralaštvo narodnoga genija, kozmopolitizam i izvornost, Novak primjenjuje spoznaje svojega suvremenika muzikologa, sakupljača narodnoga blaga, skladatelja i kritika Franje Ksavera Kuhača. Sastavom i sadržajem Zlatanićevih kompozicija, "udesba" iz glazbene literature posvjedočuje Novak vlastite nazore o estetici glazbe i njezinu razvitku, glazbi što napreduje $s$ duhom vremena. Novak glazbeni literat ili glazbeni pisac koji domišlja "specifične jezične 'kompozicije'"8, djeluje istodobno kao glazbeni kozmopolit i zagovaratelj narodnoga glazbenoga duha kako u glazbenoj poduci tako i u širenju glazbene znanosti, svjedočeći pritom o glazbenom životu Hrvatske i Europe druge polovice 19. stoljeća i ostvarajima hrvatskih glazbenika obilježenih smjerovima njihove glazbene naobrazbe i utjecajima podupiratelja na europskim glazbenim učilištima i izvan njih, u romanu $D v a$ svijeta utjelovljenih u likovima Jahode, Lipovskoga i Irme Lešeticke.

Svojim iskustvom pisca o glazbenoj povijesti i pedagogiji te spremnosti skladatelja, poznavatelja glazbopisa za orgulje, u svojem pripovjednom eksperimentu Dva svijeta zastupa načela programne glazbe, čineći izmjenu stavačnih slika jedne glazbene fantazije podlogom svojem romanesknom imaginariju. Fantazija će postati retoričkom strukturom za predstavljanje Zlatanićeva glazbenoumjetničkoga putovanja smjerom umjetničke, programne glazbe skladatelji koje "...nastoje da glazbom nešto izvanjega, drugotnoga prikažu, nego što je glazba sama (...).dakle hoće da glazbom nešto drugo rišu iz prirode, primjerice morsku tišinu, večer, jutro, boj..."9 Zlatanić slijedi svoju skladateljsku ambiciju prema glazbenom obliku orkestralne fantazije, ili fantazije što je Novak u svojoj Povijesti glazbe naziva glazbenom karakternom slikom. Označujući pomak od ilirskih vremena "zarodaka glazbene umjetnosti" reprezentativna glazbena fantazija u nas nosila bi individualni, autorski biljeg i potvrđivala narodni glazbeni duh. ${ }^{10}$ Pripovjedni oris stvorene simfonijske fantazije "Himne ljubavi" Novakova Zlatanića stapastoga obradbe izvornih slavenskih motiva s varijacijama motiva iz glazbenog opusa najznamenitijega hrvatskoga glazbotvorca Zajca. ${ }^{11}$ Amadejevo navraćanje na domaći baštinski konglomerat glazbenih toposa, motiva i tema ujedno implicira junakovu svijest

\footnotetext{
${ }^{8}$ V. ŽMEGAČ, 2003, 204.

${ }^{9}$ S. MAJER-BOBETKO, 1993/1994, 62.

${ }^{10}$ S. MAJER-BOBETKO, 1993/1994, 118.

${ }^{11}$ S. MAJER-BOBETKO, 1993/1994, 122.
} 
o vlastitoj glazbenoj podlozi čijeg se je značenja Novak uvelike dohvaćao u pripravi svojeg rukopisa opće glazbene povijesti.

Novakovo označivanje Zlatanićeve skladateljske emancipacije umjetničkom glazbom u formi popijevke ili samopijeva na tekst Lava Vukelića "Ja te ljubim, moj uzore što se ljubit ikad more", sonate za glasovir i gusle ("Pjesma bez riječi"), fantazije (ciklus 'Himna ljubavi': "San", "K Adelci", "Ti si moja"; završnoga stavka u gis-molu "Nocturno"), bachovske fuge, balade (na Šenoinu pjesmu "Smrt Petra Svačića"), simfonije ("Jutro") i gudačkoga kvarteta (četveroguđa) "Adagio", njegov je pomišljeni izlazak iz stasisa jednog prostora dekadencije nakon što providi da "...takva je sudbina siromašnih talentiranih ljudi i malenih naroda..."12.

Novak će posegnuti za isticanjem propedeutičkoga potencijala glazbe usuprot zaprjekama kulturnog paternalizma, neznanja, diletantizma, glazbene konvencije i imitacije. Težnju Amadeja Zlatanića za dokazivanjem individualne autorske vrsnoće novim djelima (njegova skladba za orgulje na svečanosti Lešecitkoga doživljuje mlak prijem, no pobuđuje oduševljenje Irme Lešeticke koja je glazbu učila na Bečkome konzervatoriju), prati prosvjetiteljski poriv za obnovom gradskoga pjevačkoga društva. Skladatelj Amadej suočava se s neutemeljenim kritikama svojeg "Adagia", "radnjice s većinom poznatim motivima" u zagrebačkim novinama za kojima se povodi njegova Adelka. Stvaralački zanos postupno slamaju prosudbe glazbenog amatera Mesarića da je Amadej prepisivao Mozarta te preuzimao dijelove "Strijelca vilenjaka", a njegova izvedba Chopinove balade zasjenjena je nastupom mjesnoga tamburaškog orkestra. Novak razvija "oblik glazbene misli"13 u pripovjednome tkivu; budući da nam njegova glazbotvoračka misao iz orkestralnog, orguljaškog/glasovirskog djela nije poznata, najbliža nam je ova Novakova glazbeno-pripovjedna parafraza o dodiru izvanknjiževnog i književnoga semantičkoga polja.

\section{Glazbeni izraz Amadeja Zlatanića}

Zlatanićev skladateljski rukopis, obilježen glazbenim utjecajima, prije svega improvizacije "L'Adieu" njegova prvoga učitelja Čeha Jana Jahode, oblikuju upravo složeni glazbeni oblici gudačkog kvarteta (četveroguđa) i simfonije ("simfonička pjesan polifonih stavaka"14). Haydnov pečat na

${ }^{12}$ V. NOVAK, 2009, 290.

${ }^{13}$ S. MAJER-BOBETKO, 1993/1994, 91.

${ }^{14}$ S. MAJER-BOBETKO, 1993/1994, 50. 
komornoj formi kvarteta, ali i Haydnov glazbeni razvoj tijekom kojega je, prema Franji Ksaveru Kuhaču u radu Joseph Haydn i hrvatske pučke popijevke", obrađivao narodne slavenske motive, ${ }^{15}$ Novak pretače u trag i nadahnuće upisane u Zlatanićev skladbouk, Amadejevim riječima: "...motivi glazbene misli hrvatskoga naroda mogu dati građe umjetniku, kao što je veliki Haydn znao sačiniti veličanstvene glazbene gradnje koje nas zadivljuju jednako kako nas zadivljuje duhovita poezijom oživljena pjesma, ili slika, i kip."16

Iz Zlatanićeva "Adagia iz četveroguđa" kao tvorbeno zahtjevne glazbene vrste koja se oživljuje u osvit modernizma iščitavamo Novakovu uputu na glazbenopovijesno značenje sonate za gudački kvartet sve od njezina utemeljitelja Haydna. Odabir novodobnoga četveroguđa za Amadeja Zlatanića formativne je naravi jer ono svojom složenom strukturom afirmira autorstvo te naglašuje pripadnost europskoj glazbenoj tradiciji. Ovaj zahtjevni komornoglazbeni oblik i pravu provjeru skladateljske vještine Novak izdvaja u pripravi svojeg udžbenika Povijesti glazbe, utječući se za tu svrhu važnome glazbenopovijesnome vrelu suvremenika Franje Ksavera Kuhača pod naslovom Prilozi za povjest južnoslavenske glasbe (1877.) Kuhač je sakupio i objavio brojne primjere hrvatskih narodnih napjeva koji su ugrađeni u kompozicije Josepha Haydna, rodonačelnika temeljnoga oblika komorne glazbe u osamnaestome stoljeću. Tako hrvatska narodna pjesma "Oj Jelena, Jelena, jabuka zelena" čini podlogu teme finala 104. Londonske simfonije, dok je melodija njemačke nacionalne himne proizišla iz napjeva "Stal se jesem rano jutro malo pred zoru" poznatog u Mariji Bistrici, Sv. Ivanu Zelini, Međimurju i Gradišću.

Glazbeni iskaz Amadejev prepunjuje njegove solilokvije. Zajedno s "vestalkom u hramu tonova" Irmom Lešetickom glazbuje izvodeći u vrtu i salonu Lešetickih glazbu romantičara Griega, Jensena, Schumanna i Schuberta, "glazbenih pjesnika i majstora efektnog ilustrovanja slika". ${ }^{17}$ Zanimljivo je da Novak podastire samo ovu pripovjednu uputu na Gustava Jensena (1843. - 1895.) njemačkoga skladatelja komorne glazbe, violinskoga virtuouza i profesora glazbe, ne navodeći ga među autorima svojeg glazbenopovijesnoga prikaza. Amadej će uz glasovirski nastup u Irminu spomenaru zabilježiti: "...Naš je život beskonačna disonanca, prekinuta samo gdjekada kratkim konzonantnim akordom..."18 Sve Amadejeve razrade odabranih glazbenih vrsta pojačavaju

\footnotetext{
${ }^{15}$ S. MAJER-BOBETKO, 1993/1994, 126.

${ }^{16}$ V. NOVAK, 2009, 400.

${ }^{17}$ S. MAJER-BOBETKO, 1993/1994, 79.

${ }^{18}$ V. NOVAK, 2009, 165.
} 
napetost, dualizam između disonantnih i konsonantnih intervala ${ }^{19}$. Tumačenje opreka tonalitetnih sustava tradicionalne dijatonike i modernističke kromatike u monolozima Amadeja Zlatanića postaje pripovjedni slog za karakterizaciju $\mathrm{i}$ oris junakovih afektivnih stanja $u$ otporu pripadnim glazbotvoračkim i glazbenokulturnim praksama.

Fantazmagorične slike Amadejeve pounutarnjene glazbe dok se kreće predjelima "među nebom i zemljom" u dvanaestome poglavlju drugoga dijela romana razvijaju se kroza pripovjedni tour de force i slobodni neupravni govor poput ritmiziranih stavaka glazbenoga djela: "...Kraj puta: onostrani velebni svijetli hram Svarogovo je djelo u kojem čuje vilinski zbor izvoditi svoju 'Himnu ljubavi'..." ${ }^{20}$ Disonantna glazbena kulisa na ulazu u hram prelazi u skladne tonove Beethovenova fugata i kulminira poezijom tonova i anđeoskom melodijom vlastite kompozicije -"Himne ljubavi". U središtu je toga stvorena poretka ljepota, harmonija, akord:"...onaj veliki jedinstveni sklad što ga intuitivno osjećaju samo veliki, odabrani duhovi i žeđaju za njim nespokojnom žeđom duše, koja se na ovoj zemlji ne utoljuje nikada..." ${ }^{21}$ Nezavršeni su to stavci Amadejeve himne koja ne dospijeva do svojih primatelja - moguće ju je razumijevati jedino iskustvom odijeljenosti pojavnoga $\mathrm{i}$ duhovnoga. Oblikujući Amadejevo kretanje "između individualističke duševnosti i manjeviše površnih konvencija, a time i sukob u kojemu društvene ustanove (često naručitelji umjetničkih djela) imaju svojom moći i svojim ukusom prevlast nad umjetnikom"22, Novak prisnažuje književnome kompleksu disocijacije senzibiliteta kao središnjoj kategoriji modernizma.

\section{Ishodišta glazbenog stvaralaštva u romanu Dva svijeta}

Novakovi glazbeni navodi potkrjepljuju postupak probiranja zamisli za vlastite (dosad nepronađene) skladbe o naravi i obliku kojih možemo zasad tek nagađati, a u kojima primjenjuje, poput svojeg učitelja i ravnatelja orguljaške škole u Pragu Zdeneka Sucherskog, teorijsko-praktična znanja o skladbouku i harmoniji. Da je Novaka glazbenoga pisca zaokupljao razvitak forme uvertire i simfonije kao uvod u operu, svjedoči posebno poglavlje njegova rukopisa Povijesti glazbe. ${ }^{23}$ Novak upravo simfoniju izdvaja onom instrumentalnom

\footnotetext{
${ }^{19}$ S. MAJER-BOBETKO, 1993/1994, 159.

${ }^{20} \mathrm{~V}$. NOVAK, 2009, 394.

${ }^{21}$ V. NOVAK, 2009, 203.

${ }^{22}$ V. ŽMEGAČ, 2003, 226.

${ }^{23}$ S. MAJER-BOBETKO, 1993/1994, 71.
} 
ilustracijom koja u sretnome spoju sa sadržajem potvrđuje skladateljsku individualnost. Utemeljiteljska simfonijska djela Haydna (Stvaranje svijeta), Mozarta (Simfonije u g-molu, es-duru, C-duru), Berlioza (Symphonie phantasique; Episode de la vie d'un artiste) i Beethovena (Deveta simfonija na Schillerov tekst Hymne an die Freude/Ode radosti) iznikla iz programnoga prijenosa književnine u glazbu postaju uzorima Amadejeva skladateljskoga postupka.

Amadej transkribira "Adagio" iz Beethovenove Appassionate, Sonate za glasovir br. 23 u f-molu, i upoznaje simfonijske radove Beethovenovih romantičkih nasljedovatelja Schumanna i Liszta. Novakovi glazbenopovijesni uvidi, primjerice o Lisztovim weimarskim Simfoničkim piesnima $^{24}$, korespondiraju s Amadejevim kazivanjem o glazbenome tkanju, i s promišljanjem Novaka pripovjedača o glazbi koja nalazi svoje mjesto $u$ književnosti.

Dvořakovu ravnanju izvedbom vlastite kompozicije za zbor Stabat mater, s pjevačkim društvom "Hlahol" i orkestrom u praškome Rudolfinumu, Amadej oduševljen nazoči, "ponesen glasovljem (...) on je negdje u eterskim visinama slušao eterskim jezikom glazbe govoriti neviđena lica bol: Stabat Mater dolorosa..."25. Glazbene fantazije Dvořaka i Lisinskoga (njegova Fantazija vrhu slavjanskih napjeva) naznačuju se mogućim ishodištima glazbenoga tragalaštva Novakova Amadeja Zlatanića, čijim se glazbenim inovacijama opire ne samo neznalački svijet već i poznavatelji glazbe.

Za karakterizaciju glazbenika-protagonista Zlatanića i sliku stanja hrvatske glazbene kulture posljednjega desetljeća devetnaestoga stoljeća, pripovjedač Novak upravlja pogled prema ovdašnjim devetnaestostoljetnim skladateljima te izučavateljima i promicateljima glazbe, prije svih Franji Ksaveru Kuhaču (Ilirski glazbenici) i Vjekoslavu Klaiću koji su u svojim radovima primjenjivali ideje o međusobnom glazbenom utjecaju - kulturnom transferu, glazbotvorstvu i izučavanju glazbe u europskome glazbenome polju devetnaestoga stoljeća. Berliozov učitelj Čeh Antun Reicha, koji je učio od Haydna i Mozarta baš kao i profesor pjevanja i orguljanja Praškoga konzervatorija Sucharsky, sačinjaju prototip Zlatanićeva učitelja Jana Jahode. Muzikolog Franjo Ksaver Kuhač progovara iz iskustva tuđine:"...Pa čim više napredujemo u glazbi po receptu kozmopolitizma, to se više otuđujemo biću svojemu..."26

${ }^{24}$ S. MAJER-BOBETKO, 1993/1994, 86.

${ }^{25}$ V. NOVAK, 2009, 279.

${ }^{26}$ S. MAJER-BOBETKO, 1993/1994, 125. 


\section{Sinkretični metajezik glazbene umjetnosti}

Novakov predmodernistički govor glazbe u službi karakterizacije Amadeja Zlatanića, skladatelja i kapelnika koji se kreće srednjoeuropskim kulturnim krajolikom najavljuje glazbenoumjetnički metajezik kao osnovicu iskaznim dionicama psihološkoga, a napose modernističkoga romana (Janko Polić Kamov, Miroslav Krleža, James Joyce, Thomas Mann). Govorom spekulativne znanosti o nastajanju glazbene umjetnosti Novak u romanu Dva svijeta uspijeva orisati proces dezintegracije stvaralačke osobnosti koja se, kako napominje u svojem spisu glazbene povijesti, "uzvinjuje do individualnosti"27, uz tragičnu ironiju neprepoznavanja hrvatske europejštine i njezinih umjetničkih manifestacija u radovima darovitih glazbotvoraca ali i glazbenih pisaca.

Novakov odabir autorskih imena iz postava europske glazbene tradicije (Bach, Haydn, Mozart, Beethoven, Schumann, Schubert, Brahms, Wagner; Grieg; Gounod; Scarlatti, Tartini, Verdi, Bellini; Smetana, Dvorak; Čajkovski; Lisinski, Zajc) te uz njih vezanih značenja glazbenih forma i recepcije glazbopisanja, promišljeno konfiguriraju turbulentno glazbeno putovanje Amadeja Zlatanića, Zlatanićevu osobnu disonancu i iznevjerenje umjetničkih pregnuća u kolopletu rečenih kulturnih politika. Novak problematizira teme glazbenog ukusa i glazbene naobrazbe domaće sredine, rudimentarne naobrazbe lokalne zajednice i njezinih "akroamatijskih primitivnih dijelaka" što tradicijsko i popularno pretpostavljaju umjetničkoj, autorskoj glazbi i profaniraju glazbenu misao ${ }^{28}$. Razumijevanjem glazbenog jezika, ali i cjeline glazbene povijesti, glazbene umjetnosti iz svijeta obrazovanih naroda "... nastojimo se naći po svojoj kulturi s njima u jednom kolu, u kojem svojim tamburicama ne ćemo nikada uloviti mjesta..."29

\section{Zaključak}

Amadejevo snatrenje o čistoj umjetnosti, u modelativnome svijetu glazbe obilježenih univerzalnim stvaralaštvom Bacha, Mozarta, Haydna, Novak osnažuje rijetkim primjerima umjetničkoga patronata i zagovora njegovih skladateljskih i izvedbenih pregnuća među istinskim dionicima glazbene kulture. Pretega reproduktivne glazbene prakse u obliku koračnica,

${ }^{27}$ S. MAJER-BOBETKO, 1993/1994, 74.

${ }^{28}$ V. NOVAK, 2009, 238.

${ }^{29}$ V. NOVAK, 2009, 399. 
polka i valcera, ili preuzimanja na način naturalista i glazbenog amatera, kotarskoga pristava Mesarića kojega Amadej podučava glasovir da bi najzad, nuždom natjeran, uglazbio njegovu nemuštu koračnicu posvećenu željeznici. Amadejev "Adagio" zapažaju Lipovski, pokrovitelji čeških umjetnika, no istodobno on hlepi za skladateljskom slavom na domaćim stranama, $\mathrm{u}$ Zagrebu. Za nj zbilja postupno gubi obrise i postaje dijelom stilskog registra vlastitoga neomeđena svijeta, putovanje predjelima nadsferične glazbe. Svestrani Antun Vesely, iskusni glazbeni znalac irelativist, pretkazuje dokinuće Amadejeva umjetničkoga poslanja.

Amadejev glazbenički profil, izveden iz njegovih glazbenih odabira i čitanja te nagnuća, umnogome odslikava njegov ljudski značaj. On je po naravi glazbe kao svojega "svetoga pozvanja" stvaralac djela neomeđenih zahtjevima jednoga vremena, njegovih nositelja, pripadna im znanja o svijetu i ukusa. Izgubiti dotjecaj s vlastitim glazbeničkim uporištem znači popustiti pred neumjetničkim, pragmatičnim, izvanjskim svrhama koje glazbu pretaču u jednokratan posao izvedbe i repeticije.

\section{Literatura}

\section{Izvor}

Vjenceslav NOVAK, Dva svijeta, u Krešimir NEMEC, Otrov u duši - izbor iz djela Vjenceslava Novaka (Posljednji Stipančići; Dva svijeta; Nezasitnost i bijeda; U glib; Iz velegradskog podzemlja), Mozaik knjiga, Zagreb, 2009, 229-432.

\section{Knjige $i$ članci}

Nikola BATUŠIĆ - Zoran KRAVAR - Viktor ŽMEGAČ, Književni protusvjetovi: Poglavlja iz hrvatske moderne, Matica hrvatska,Zagreb, 2002.

Sanja MAJER-BOBETKO, Povijest glazbe Vjenceslava Novaka, Časopis Croatica: Časopis za hrvatski jezik, književnost i kulturu, 25, 40-41, 1993/1994, 1-172.

Sanja MAJER-BOBETKO, Estetika glazbe u Hrvatskoj u 19. stoljeću, JAZU, Zagreb, 1979.

Viktor ŽMEGAČ, Književnost i glazba, Intermedijalne studije, Matica hrvatska, Zagreb, 2003. 


\section{THE MUSICAL MATERIAL OF THE NOVEL DVA SVIJETA BY VJENCESLAV NOVAK}

\section{Summary}

In the psychological novel of the turn of the century Dva Svijeta (Two Worlds) the musician Amadej Zlatanić reflects upon his creative potential in the cultural area of the Austro-Hungarian Monarchy.

The domestic space of the denied affiliation weakens the visibility of the Croatian name, and social conventions threaten Zlatanić's artistic, strengthened by musical schooling, integrity. Novak achieves a hero's initiation into the musical universe with the syncretic metalanguage of the musical art.

Musicologist Sanja Majer-Bobetko found Novak's overview of European musical history. With the novel Dva Svijeta Novak applies his own propaedeutic experience of the transfer of musical forms into narrative forms. Novak's representation of the duality of the apparent and imagined world is a building block of the novel about becoming an artist. Translating the language of music into a proto-modernist narrative expression, Novak questions the perspective of Croatian artistic identity in the said historical-cultural order.

Keywords: Vjenceslav Novak, Dva Svijeta (Two Worlds), history of music, novel, syncretism 